\title{
Other Fecundities: Proust and Irigaray on Sexual Difference
}

Luce Irigaray's critique of phallocentrism in the 1970s and 1980 s provoked a sea change in feminist philosophy. Neither man's opposite nor his homologous equal, woman emerged as "this sex which is not one" - "neither one nor two," but rather a mode of self-relation resisting any fixed identity and enabling multiple forms of sensual pleasure (This 26). In her readings of the seminal texts of Western thought, from Plato to Freud and beyond, Irigaray worked to expose and undermine false oppositions between sexuality and motherhood, intimacy and integrity, and between different sites of bodily pleasure. In "The Fecundity of the Caress," for example, she argues for a generous interpretation of the mutually regenerative possibilities of sexual pleasure. She criticizes Levinas for situating this pleasure within the context of childbirth-in particular, the birth of a son-such that the woman's body becomes merely a means to an end, a vessel for the reproduction of the father's identity and responsibility. For Irigaray, there is already an event of rebirth in the mutual exchange of caresses between lovers; pleasure brings us back to life and back to the roots of life in the maternal body. ${ }^{1}$ Even as we are called back to the site

Volume 21, Number 2 DOI 10.1215/10407391-2010-002

(C) 2010 by Brown University and $\mathrm{d}$ i f f e $\mathbf{r}$ e $\quad$ c e $s$ : A Journal of Feminist Cultural Studies 
of our own birth, the caress calls us forth to new sources of regeneration and rebirth, not all of which are strictly reproductive. This circulation of pleasure interrupts the instrumental logic whereby our own bodies become tools for the accomplishment of certain tasks, and the bodies of others become aids or hindrances to these tasks.

This early work of Irigaray seeks to multiply possibilities for women's self-expression by recovering a suppressed sexual difference in which male and female are neither the same nor opposites but are rather irreducibly different modes of embodiment. In her more recent work, however, Irigaray has emphasized the duality of sexual difference at the expense of multiplicity. ${ }^{2}$ In I Love to You, she claims that "across the whole world, there are, there are only, men and women" (47; emphasis added). ${ }^{3}$ Racial and other differences are subordinated to this fundamental sexual duality, and Irigaray argues that they only find adequate expression on the basis of the latter. ${ }^{4}$ The heterosexual couple becomes the model not only for sexual difference but also for ethical and political life. ${ }^{5}$ In Democracy Begins between Two, Irigaray writes: "I cannot avoid the conclusion that woma(e)n and ma(e)n represent two different worlds, two visions of the world that remain irreducibly distinct" (151). The main contours of this difference are carved by ways of engendering and being engendered. Women are engendered in a body that is of the same gender, they procreate within their own bodies, and they are able to nourish others with their bodies. Men are born to a different gender, they procreate outside of themselves, and their bodies are not able to nourish others directly (151). According to Irigaray, women are thereby more inclined toward intersubjectivity, relations with the other gender, the physical environment, and the present or future tense, while men favor subject-object relations, the construction or fabrication of worlds, instrumentality, relations to abstract entities like the nation and justice, and "the past determining the present and the future" (153). Irigaray criticizes androgyny as a passing fad that offers what may seem to be an "ethical solution to the division of the genders" but turns out to be "delusional," "decadent," and "weird" unless it takes "sexual difference as both its setting out point and its destination" (Je 122-23). ${ }^{6}$

Irigaray offers a trenchant critique of the patriarchal monoculture that fails to recognize sexual difference, and so represses women's voices, bodies, and ways of being. But her recent focus on the duality of the sexes, and her apparent suspicion of multiplicity, lead to problems theorizing other forms of difference such as race, culture, and sexuality, and it may prematurely disqualify possibilities for imagining sexual 
difference beyond the magical “two.” Even Alison Stone's recent revision of Irigaray, which attempts to reconcile her account of sexual duality with bodily multiplicity as a way of addressing the exclusion of intersex bodies in her work, still maintains the primacy of duality and in my view fails to address claims of multiplicity on its own terms. In what follows, I test the limits of Irigaray's approach to sexual difference through a reading of Proust's novel Sodom and Gomorrah, in which I develop a model of sexual difference based on an irreducible duality of sexual "parts," both of which may be found in the same individual but that nevertheless relate to one another and so become meaningful only through the circulation of an incongruous third element or libidinal force that generates multiple forms of pleasure and fecundity. Proust's novel opens with an extended comparison of a sexual encounter between two men to the fertilization of a rare orchid by a bumblebee; the men connect to the sexual difference in themselves and in the other through their mutual enjoyment of pleasure across a threshold of alterity that is as mobile and contingent as it is irreducible to sameness. In my reading, this scene from Proust suggests a flexible way of accounting for practices that complicate the sexual duality of male and female without dissolving it, but also without enshrining it in the figure of the heterosexual couple. As such, it promises to open new ways of theorizing sexual difference in contexts where "to be two" is simply not enough.

\section{Irigaray and the Limits of Sexual Difference}

Alison Stone's recent analysis of Irigaray's later work addresses precisely the concerns I have raised here about the relation between duality and multiplicity. In Stone's reading, Irigaray is a realist essentialist, which means that she believes in a natural, irreducible, and really existing sexual duality. ${ }^{7}$ This duality has yet to find adequate cultural expression; under patriarchy, and even under certain forms of feminism, sexual difference is reduced to an explicitly neutral but implicitly masculine monoculture of humanity. For Stone, Irigaray's concept of sexual difference is best understood in terms of different rhythms or temporalities such as expansion and contraction, which are linked in a process like breathing where "each pole, alternately, inhales and exhales air, so that the one expands while the other shrinks" (Luce 9o). Female rhythms, like female sexual development, are depicted as irreversible and discontinuous; they are 
connected to cyclical processes in nature like the change of the seasons. Male rhythms, on the other hand, are characterized by homeostatic processes that hover around an ideal mean, building up tension and releasing it while maintaining a steady equilibrium. Stone locates these processes not only in sexed organisms but also in more diffuse natural processes like weather or the growth of plants; ultimately, she draws on German Romantic thought to fill in a more general account of male and female principles operating in all of nature (Luce $\left.9^{2-93}, 138-43,154-60,193-215\right)$.

Stone frankly acknowledges the limits and potential problems of Irigaray's realist essentialism. It is simply not the case that every woman experiences her body in terms of irreversible cyclical rhythms, and the reason for this is not merely because our culture fails to give expression to innate female rhythms. Even in a feminist utopia, it is not clear that each and every woman would identify with Irigaray's account of our "real" natures, nor is it clear that everyone who identifies as a woman would count as such for Irigaray. The conviction that there are two and only two sexes marginalizes an experience of bodily multiplicity that is just as phenomenologically real and compelling as the experience of sexual duality (Luce 85, 112-13). Irigaray's repeated suggestion that the only genuine encounter with difference can happen between the two sexes enforces a heterosexual paradigm that marginalizes same-sex relationships (Luce $7,48,189-90,221-22)$ and makes it impossible for Irigaray to account for intersex or transsexual bodies without characterizing them as aberrant or unnatural (Luce 49, 113-21).

Stone seeks to address these problems in Irigaray's work by supplementing her theory of sexual difference with an account of bodily multiplicity that she develops in conversation with Judith Butler, Friedrich Hölderlin, Friedrich Nietzsche, and F. W. J. von Schelling. Stone defines bodily multiplicity as "pre-conscious impulses to pursue particular kinds of activity" (Luce 7$).{ }^{8}$ These impulses provide a motivation to subvert gender norms that illegitimately restrict the manifestation and expression of our vital forces, but they do not in themselves provide a way of explaining why or how we are sexed. Multiple forces are just that-multiple rather than dual-so there is no good reason, according to Stone, to call some of these forces male and some of them female (Luce 81-83, 120). ${ }^{9}$ While Stone agrees with Irigaray that nature is characterized by male and female rhythms of expansion and contraction, she also believes that multiple bodily forces tend to break up these rhythms and differentiate them. For Stone, sexual duality is fundamental and real, but it nevertheless has the 
tendency to split itself apart into a multiplicity of different nonsexuate forces that would threaten to dissolve sexual difference if they were not also limited by the dual rhythms of the sexes (Luce 8-9, 158-59, 210-14). While for Irigaray, male and female forces limit one another like alternating movements of a process such as breathing, for Stone, duality and multiplicity limit one another, with duality restricting the otherwise irreparable shattering of multiplicity, and multiplicity differentiating the otherwise stultifying and restrictive duality of the sexes. Both are real, natural tendencies, and both should find cultural expression-although for Stone, as for Irigaray, sexual difference has an ontological, political, and even ethical priority over bodily multiplicity.

What reason do we have to accept this rather complicated (if also fascinating and provocative) account of mutually limiting tendencies? Stone draws inspiration from Hölderlin and Schelling, for whom sexual difference is a necessary starting point but not an end point or unchanging reality. By supplementing Irigaray with a German Romantic philosophy of nature, Stone hopes to provide the theoretical foundations for a self-critical culture of sexual difference that overcomes the problems she has identified with Irigaray's own version of her theory (Luce 219). But the problem with these Romantic sources is, quite simply, their Romanticism; even with Stone's modifications, they still offer a conservative, even nostalgic view of sexual difference and the diversity of sexual life. For example, Hölderlin roots sexual duality in an originary unity that-to be sure-spontaneously splits in an endless process of self-differentiation, but it nevertheless also recapitulates a biblical narrative of fall and redemption (Luce 155). For Hölderlin, the originary unity of nature is "still and peaceful in its lack of differentiation" and only subsequently falls into self-diremption and conflict, whereupon it is our task as human beings to reunite with nature in a way that gathers together these broken fragments into a new, self-differentiated unity (Luce 155). While this narrative can certainly be interpreted in ways that resist the conservative narrative of fall and redemption, the difficulty of this interpretive work results in a needlessly complicated and even counterintuitive account of the relation between duality and multiplicity. For example, Stone asks:

[I]f bodies' tendencies to develop multiple characteristics would be strengthened were sexual duality to be fully realized, then doesn't my position have the fantastic implication that a sexuate culture would stimulate all bodies to develop-physically_beyond being 
sexed? To avoid this implication, we need to suppose that there is an active counter-tendency of bodies to reinstitute their sexed character against their own tendency to dissolve it. (Luce I58)

But if we must suppose that bodies have tendencies both to self-differentiate and to retain or even return to their earlier sexed character, why would we not also suppose a tendency to return to their even earlier presexed or unitary character? There may be ways of making Hölderlin work for feminist theory, but given the highly speculative suppositions this seems to require, there are also good reasons to look elsewhere for inspiration.

Similar problems arise with Stone's appeal to Schelling. Schelling posits an originary Indifference that spontaneously expresses itself as two opposed forces, one of which is more productive and expansive, the other more inhibiting or restrictive. For Schelling, the sexual character of these forces is clear: the male is productive, and the female restrictive. "This preponderance of activity on the male side suggests that it is the male who actively initiates sex and reproduction, and through whom natural productivity strains beyond the sexual polarity in which it has become fixed" (Luce 204). The social hierarchy of male over female is naturalized in Schelling's account of nature; and again, while it is certainly possible to interpret his theory of nature differently in order to problematize and resist this hierarchy, there are also reasons to believe that the theory's basic principles thwart, rather than advance, Stone's feminist project. Stone finds herself wrestling with similar issues in both Schelling and Hölderlin: resisting their claims that nature longs to return to a state of placid unity, revising their investments in traditional gender hierarchies, and dealing with the strange implication that bodies may be self-differentiating to the point of losing their sexed character (see Luce 208-9 for a negotiation of this problem as it arises in Schelling).

The result of Stone's revisions is a hybrid view that may have a certain explanatory power but that still sounds like a more sophisticated version of Men Are from Mars, Women Are from Venus: "Fusing Schelling's and Irigaray's frameworks, we might say that males, being predominantly active, have a compulsion to activity which occasionally becomes punctuated by rest (the interludes of 'release' which Irigaray attributes to men), while females tend to remain (faithfully or 'passively') within the specific stages of life which they have reached, while over time gradually moving towards the transition into a quite different stage" (Luce 209-10; see also Irigaray, I Love 38 ). Even with the caveat that "no human individual is 
exhaustively constituted by his or her sexed character" (Luce 210), one may still legitimately wonder: For whom is it obvious that males and females are essentially like this? Where does it leave those who do not feel "male" or "female" in these ways? How many modifications to Irigaray's theory must we make before developing new models from different starting points?

I am broadly sympathetic to Stone's approach, and I find her reading of Irigaray compelling; but her account of multiplicity, and of the relation between duality and multiplicity, is less convincing. I see little reason to believe in the mutually limiting tendencies of duality and multiplicity, especially when the view of multiplicity suggested by Hölderlin and Schelling seems so far from contemporary feminist and queer concerns. Stone's reinterpretation of Irigaray takes the challenges posed by her later work seriously and makes great strides toward addressing them; but to the extent that Stone still prioritizes the cultural expression of sexual duality as a necessary condition for the expression of multiplicity, she does not shift the theoretical ground radically enough to address these problems in a satisfying way. ${ }^{10}$ By developing a different model of the relationship between sexual duality and multiplicity in Proust, I hope to show that the former is not foundational for the latter and should not be privileged over it, but rather that duality and multiplicity are mutually co-implicating.

\section{The Bumblebee and the Orchid: Proust as "Moral Botanist"}

In the opening scene of Sodom and Gomorrah, Proust compares the mutual seduction of two men to the fertilization of a rare orchid by a fat, contented bumblebee. The scene is secretly observed by the narrator, Marcel, who has positioned himself behind a blind in order to observe the unfolding drama as a "moral botanist" (32). M. de Charlus, perceived by many of his society friends as a womanizer and a harsh critic of effeminacy in men, enters the courtyard on his way to visit a relative. But as he enters, his face is transformed into the expression of a woman. It's not just that Charlus resembles a woman in this moment, it's as if he has suddenly become one (8). The occasion for this transformation is the appearance of Jupien, a tailor with a small shop in the courtyard. Feeling Charlus's steady and intent gaze, Jupien suddenly stops in his tracks, "rooted like a plant" (8). Charlus assumes a posture of feigned indifference, in response to which Jupien sticks out his bottom and puts his hand on his hip, "striking poses with the coquettishness that the orchid might have had for the 
providential advent of the bumblebee" (8). With no time to lose, Charlus and Jupien disappear into the tailor's shop, where Marcel, determined not to miss a moment of the drama, follows quickly behind. Hidden behind "an exceedingly thin partition" within the shop (11), Marcel overhears sounds

so violent, had they not constantly been taken up an octave higher by a parallel moaning, [he] might have thought that one person was slitting another's throat close beside [him] and that the murderer and his resuscitated victim were then taking a bath in order to erase the traces of the crime. From which [he] concluded that if there is one thing as noisy as suffering it is pleasure, especially when there is added to it-failing the fear of having children, which could not be the case here [. . .]-an immediate concern with cleanliness. (I3)

The scene ends with Charlus and Jupien exchanging notes about which men in the neighborhood are open to sex with other men, and with Marcel's own reflections on the significance of the scene he has just witnessed.

While Proust's narrator offers his reflections "without the least scientific pretention to drawing a parallel between certain botanical laws and what is sometimes quite wrongly called homosexuality" (11), a close reading of this scene yields fruitful possibilities for conceptualizing sexual difference in a way that addresses the problems I have identified in Irigaray's later work. Proust's approach to sexual difference is rooted in an irreducible duality of male and female, but it is also generative of maximally diverse sexual combinations, all of which are equally natural and equally enhanced by artifice. In order to develop Proust's botanical insights further, we need to map out the sites of pleasure and patterns of circulation observed in this scene.

The language of "moral botany" owes its initial point of reference to an exotic plant owned by the Duchesse de Guermantes. The female flower of this plant can be fertilized only by an insect carrying pollen from a male of the same species, and given the unlikeliness of such a plant existing elsewhere in Paris, the female has been "exhibited in the courtyard with that insistence with which the marriageable young are thrust forward" (5). At first glance, it would seem that Jupien is to Charlus as the flower is to the bee; Jupien displays his beauty, and Charlus buzzes in to fertilize his pleasure while collecting his own nectar. But the situation is complicated by the existence within Charlus of both male and female "parts," both of which seek pleasure in different ways, in relation 
to different aspects of the other to whom he is attracted. Marcel compares Charlus to a vanilla plant:

Like so many creatures of the animal and vegetable kingdoms, like the plant that would produce vanilla, but which, because, in it, the male organ is divided by a septum from the female organ, remains sterile unless hummingbirds or certain small bees transport the pollen from one to the other, or unless man fertilizes them artificially, $M$. de Charlus (and here the word fertilization must be taken in its moral sense, since in the physical sense the union of male with male is sterile, but it matters that an individual should be able to meet with the one pleasure he is capable of enjoying [...]), $M$ de Charlus was one of those men who may be called exceptional, because, however numerous they may be, the satisfaction, so simple with others, of their sexual needs depends on the coincidence of too many conditions, too difficult to encounter. (30-3I)

The vanilla plant contains both male and female reproductive organs within itself, but since a partition divides them from one another, elaborate strategies are required in order to ensure the involvement of a third party-an insect, bird, or person-in the plant's fertilization. This suggests that, while sexual duality exists in nature, it also requires something in excess of itself in order to become fecund; a third element or force is needed for the two sexes to "communicate," both in the sense of exchanging genetic information and in the sense of touching or opening toward one another. As I will argue below, this third element is not in itself sexed male or female, but it is nevertheless sexual; as a force rather than a kind of being, it introduces movement, significance, and even temporality into the otherwise static duality of male and female.

Following Proust's suggestion to understand fertilization in its "moral sense," we may surmise that, even if sex between men does not reproduce the species - even if it raises no "fear of having children"it nevertheless connects otherwise disparate parts within the self and between self and other, thus giving rise to "the one pleasure he [or she] is capable of enjoying." On this account, no sexual encounter is by nature sterile, even if the sex is nonreproductive; one need only hook up with others who have "inside them an embryo [of either sex] they are unable to make use of" in order to fecundate both bodies through the exchange of pleasure (33). Moral fertilization is fecund in a similar sense to Irigaray's 
concept of the fecund caress: it engenders mutual pleasure for the lovers, regenerating their capacities to give and receive. For both Proust and Irigaray, fecundity is not a matter of finding your other half, the piece that fits your puzzle, in order to restore a lost organic unity, but rather a matter of connecting with an other beyond yourself to cross-fertilize the sexual difference within yourself, while maintaining the threshold that articulates this difference. ${ }^{11}$ But where Irigaray's later work imagines the threshold of sexual difference as an interval between man and woman, the Proustian model of cross-fertilization challenges us to follow the trace of the other sex within ourselves and the trace of the same sex within the other, such that the threshold of sexual difference resists being located in a single fundamental duality. Instead, this threshold is both within us and between us; the image of the septum dividing the male part of the vanilla plant from the female part does not limit the proper expression of sexual difference to an originary duality, but rather suggests that there are always (at least) two sexes, even within a single body, and that the possibilities for experiencing and understanding this sexual difference are multiplied when we connect with others in pleasurable exchange. ${ }^{12}$

The comparison between Charlus and the vanilla plant affirms the sexual duality of male and female, but it locates this duality within each body, such that different sexes become visible at different moments for those who are attuned by their own desires to see them-just as Marcel glimpses the woman in Charlus upon entering the courtyard. Marcel participates in this sexual encounter in his own way, hidden behind an "exceedingly thin partition" in the tailor's shop that recalls the partition within the vanilla plant (11). For Marcel, the encounter between Charlus and Jupien is a "miracle" (31; see also 11); "everything about it seemed imbued with beauty" (31). He buzzes around the encounter like a bee, fertilizing his own pleasure and eventually producing a narrative in which the reader may also find pleasure. Throughout In Search of Lost Time, Proust describes relationships where men "play the role of another woman for the women who love women, and the woman offers them at the same time more or less what they find in a man, so that the jealous friend suffers from feeling that the man he loves is inseparable from the woman who is for him almost a man, at the same time as he feels him almost escaping from him, because, for these women, he is something he does not know, a sort of woman" (Sodom 26). With two sexes in each body, and at least two bodies in each relationship, the possibilities for fruitful encounters are multiplied indefinitely. It may take the patience of a moral botanist to 
follow the twists and turns of these different configurations of pleasure, but there is clearly pleasure to be found in the observance and narration of such "miraculous" encounters.

\section{Cross-Fertilizing Sexual Difference}

The theory that a germ of both sexes exists within each individual proposes to think sexual difference starting from intersexuality or transsexuality rather than from the heterosexual couple. ${ }^{13}$ But to what extent does this theory contribute to Stone's and Irigaray's projects of explaining sexuation? By locating both sexes in a single body, rather than in the morphologies, rhythms, or imaginaries proper to distinct bodies, Proust can be read as mixing or confusing the sexes and so betraying or effacing sexual difference, as in Irigaray's condemnation of nameless androgynes. Clearly, Proust is not concerned to defend himself against such potential criticisms, but only to describe the particular sexuality of Charlus and his fellow inverts, sodomites, and sapphists. What follows is my own extrapolation of a theory of sexual difference based on Proust's intricate descriptions. There is no question in his text that male and female parts exist in nature and that they are required for sexual reproduction; but they exist as parts rather than as "worlds," ways of being, or even rhythmic tendencies. These parts become fruitful and meaningful only through the patterns of exchange made possible by the circulation of a third element or force that connects otherwise separate compartments. The key to fertilization, or to what Irigaray might call the fecundity of the caress, is therefore a relation to alterity without which the possibilities of sexual difference would remain inert and inactive, without communication, expression, or mutual fecundation. Marcel speculates that "[t]he laws of the vegetable world are themselves governed by ever higher laws" (7), the latter of which seem to suggest an amalgam of the taboos against incest and masturbation: thou shalt not fertilize thyself. There must be an exchange with alterity, in whatever form, by whatever awkward and circuitous paths, and with however many intermediaries, for the possibilities of sexual difference to become meaningful and fecund. The encounter with another who, like me, bears the trace of the other sex multiplies the natural duality of male and female beyond the frameworks of both nature and duality. The presence of both sexes within each body, but also their strict separation from one another, creates the need for multiple encounters with alterity, but it does not prescribe the form these encounters will take. The rarest flowers 
are also the most difficult to fertilize and must develop the most elaborate arrangements to connect with others who are able to satisfy them. ${ }^{14}$

In the case of the vanilla plant, alterity appears in the form of a bumblebee, hummingbird, or human hand that allows the two sexes to communicate. In her reading of this scene in Proust, Julia Kristeva calls the bumblebee "a motor-drive and thought. It toys with the dual nature of flowers that it secretly knows well; it flies over them and unites them. Plant imagery thus requires the bumblebee, an incongruous, foreign element that empowers plant sexuality" (84). ${ }^{15}$ It is precisely the bee's incongruity-its capacity to fly between different sexed parts without getting stuck on one side or the other, but also without remaining indifferent to multiple forms of sexual allure-that makes it a perfect figure for the circulation of pleasure across thresholds of sexual difference. One can imagine the bee saying, along with Angela Carter's character, Dr. Hoffman, "All things co-exist in pairs but mine is not an either/or world. Mine is an and + and world. I alone have discovered the key to the inexhaustible plus" (206). ${ }^{16}$ The bee does not merely connect the dots between two poles of sexuate life; in circulating between localized sites of sexual difference, the bee also fertilizes their meaning, making possible their "communication." The female is no more passive, receptive, or faithful than the male in this exchange; when the insect enters the male flower, his stamens "spontaneously [turn] so that the insect might the more easily receive him; similarly, the flower-woman that was here would, should the insect come, arch her 'styles' coquettishly and, in order to be penetrated more fully by him, would imperceptibly, like a hypocritical but ardent young damsel, come to meet him half-way" (Sodom, 6-7). Depending on its context, the bee is like a woman or a man, giving and receiving differently in relation to different flowers; it penetrates both male and female flowers, but it also receives the seed of the male flower it penetrates. The sex of the bee cannot be determined as either male or female in this narrative; it remains the vector of an almost indifferent-but not for this reason neutral or asexual-pursuit of pleasure, servicing many plants while following its own distinct agenda. The circulation of this ambiguous force sustains an economy of pleasure in which multiple needs are met, such that a gain on one side does not necessarily require a loss on the other. In contrast with the economy of desire in Marcel's relationship with Albertine, where desire presupposes distance and collapses upon attaining the desired object, the botanical economy of pleasure does not follow a logic of lack, fulfillment, and disappointment, but rather of diffuse, multiple connection. ${ }^{17}$ 
The bee is not just a metaphor; it is a force that motivates and sustains the circulation of pleasure between male and female localizations that only become meaningful through their specific modes of communication or relation. The bee does not "represent" anyone or anything, but rather maps out patterns of exchange among sexually specific parts of statistically male or female bodies. The "higher law" regulating this circulation does not favor heterosexuality any more than homosexuality; it prescribes a cross-fertilization with the pleasure of an other, such that one plays the bumblebee for someone else-anyone else-but never only for oneself. Marcel's description of Charlus makes this law more concrete. At different moments, Charlus becomes like a bee (attracted to the rare flower, Jupien), like a male flower (fertilizing Jupien's pleasure with his own), and like a woman (upon encountering Jupien in the courtyard). ${ }^{18}$ These positions are inherently unstable, for even as Charlus fertilizes the pleasure of Jupien, he, too, becomes like a flower whose pleasure is fertilized by Jupien, the latter of whom belongs to that rare "sub-variety of inverts destined to ensure the pleasures of love to the invert who is growing old" (32; see also 11). Distinctions between giving and receiving, fertilizing and being fertilized, active and passive, become impossible to separate out or to locate in one body rather than the other. Jupien is fertilized by Charlus, who awakens in him the capacity to fertilize Charlus himself. ${ }^{19}$ At every stage of the drama, pleasure is exchanged over the threshold of sexual difference, between male and female "parts"; but as the drama unfolds, the significance and the lived experience of this sexual difference shifts according to relations of giving and receiving that cannot be isolated in one direction or the other. The implication seems to be that sexual difference does not inhere in any one of these bodies as a stable essence, nor as a rhythm proper to that kind or shape of body, but is rather distributed through different body parts at different times, depending on the specific social and sexual configurations of the encounter. Even these "parts" are not fixed in their essence, but rather are specified in evershifting configurations in relation to the other(s) with whom pleasure is shared, such that fingers, mouths, beauty marks, or any other part of the body may be eroticized. ${ }^{20}$ Again, Charlus offers a concrete example. The specification of Charlus's vanilla-plant sexuality depends on the others to whom he is attracted at this or that moment and on the way he finds pleasure with these others. We may discern a pattern or rhythm specific to Charlus, but it makes little sense to say either that Charlus is a man or that he is a woman. His "sex" depends on the particular ways he attempts 
to negotiate pleasure in this or that situation. ${ }^{21}$ My point is not that we should abandon the terms man and woman, but rather that we need to situate them within the economies of pleasure and sexual difference that fertilize their significance.

Proust's emphasis on an exchange of pleasure between sexed parts, rather than on the rhythms or tendencies of real essences, as in Stone's reading of Irigaray, suggests that even if a more or less stable duality of male and female can be identified in nature, there is nothing about this duality that prescribes or limits the meaning of sexual difference. Duality is a starting point, not an end point; the significance of sexual duality unfolds through exchanges between bodies seeking the difference of the other and the implicit differences within themselves. What matters here is not which part goes where, but rather how these parts are put in circulation with each other, to whose benefit and whose loss-or ideally, whose mutual fecundation. This approach to sexual difference is consistent with Irigaray's early insights into the general economy of feminine pleasure, its exploitation by a phallocentric model of lack and compensation, and the reduction of women's bodies-especially our reproductive body parts - to commodities (This 31-33, 170-97). It also resonates with some of her later work on wonder (Ethics 62-70), the placental economy ( Je 37-44), and the "angels" who act as messengers across the threshold of sexual difference (Ethics 15-16; Sexes 35-39). My aim is to connect these early and late insights to an explicitly diverse account of sexuality in which duality and multiplicity are logically co-implicating, in resistance to a dualist ontological foundation whose expression is both necessary for and limited by the expression of multiplicity.

If we are to approach human sexuality as "moral botanists," if only in a provisional and "unscientific" way, our account of sexual difference must consider both the duality of male and female and also the incongruous force that multiplies their possibilities and that ultimately exposes the duality of sex to its own contingency. For Proust, the bee is a sexual force that moves between sexed parts and is relationally but ephemerally sexed in its encounters with these parts, but it does not retain a sexual specification beyond these encounters. In this sense, the bee is akin to the multiple forces to which Stone refers in her critical modification of Irigaray (Luce 77-84); but it differs from Stone's account in that it exists only in relation to sexuate parts and so cannot be conceived as a purely nonsexuate bodily force. Rather, the bee has its sexed specificity outside of itself in the flowers, and the flowers have their sexuality, or the 
force of their interrelation, outside of themselves in the bee. ${ }^{22}$ We cannot claim a primacy for one or the other; duality is meaningless without the vectors of exchange, and exchange remains indeterminate without the material specificity of bodies. Our challenge, then, is not "to be two," but rather to think duality in the midst of multiplicity and to trace the effects of pleasurable exchange through our relationships, our social structures, and our philosophical concepts.

While critical of Irigaray's recent efforts to construct a foundational role for sexual duality, the alternative account I have developed here nevertheless remains inspired by Irigaray's work insofar as it affirms sexual difference as irreducible to the one or the same. In the Proustian model, male and female parts exist, but they have no inherent content, pattern, or tendency; what makes them meaningful, and what produces the effect of sexed tendencies or worlds, are patterns of circulation and exchange, specific practices of sexuality, and local histories of sexual encounters. Without the search for whatever rare and delicate pleasures we are capable of experiencing, the material sites of sexual duality remain sterile and meaningless. This is not to say that biological sex does not exist or does not count as "real," but that it does not mean anything without the continuous but continually shifting patterns of exchange between bodies. The multiplicity of bodily drives, and the encounters with alterity that they engender, fertilize the meaning of sexual duality; and likewise, the duality of the sexes orients and stabilizes, without thereby restricting, the circulation of multiple drives. For Proust, there is nothing unnatural about a man becoming a woman to penetrate another man who has become a woman in a different but complementary way. It's as natural as the birds and the bees! ${ }^{23}$ Far from betraying or disavowing sexual difference through their transformations, Charlus and Jupien are following its "higher law": a law that seeks pleasure with others in difference and self-differing, but for whom this difference need not appear in one particular shape or another. The local specificity of such encounters is as rich and varied as the moral botanist could hope for, and the possibilities for their expression are limited only by our patience to discover them.

Lisa guenther is Assistant Professor of Philosophy at Vanderbilt University. She is the author of The Gift of the Other: Levinas and the Politics of Reproduction (State University of New York Press, 2007) as well as articles on Beauvoir, Heidegger, Derrida, and others. She is currently working on two projects: one on theories of sexual difference and one on the phenomenology and politics of shame. 
Notes
Bringing me back to life more intimately than any regenerative nourishment, the other's hands, these palms with which he approaches without going. through me, give me back the borders of my body and call me back to the remembrance of the most profound intimacy. As he caresses me, he bids me neither to disappear nor to forget but rather, to remember the place where, for me, the most intimate life holds itself in reserve. Searching for what has not yet come into being, for himself, he invites me to become what I have not yet become. To realize a birth still in the future. Plunging me back into the maternal womb and, beyond that, conception, awakening me to another-amorous-birth. ("Fecundity" 232-33)

For a more sustained reading of Irigaray's argument in this text, see Guenther $84-89$.

She even goes so far as to claim that, without a foundation in sexual duality, "multiplicity is likely to lead to death" (I Love 143). "My first theoretical gesture was therefore to free the two from the one, the two from the many, the other from the same, and to do this in a horizontal way by suspending the authority of the One: of man, of the father, of the leader, of the one god, of the unique truth, etc." (Democracy 129). Alison Stone comments: "We can see why she links the beliefs in unity and multiplicity: to affirm multiplicity is to see it as the common, unitary, character of all bodies" (Luce 85). But it is not clear that all affirmations of bodily multiplicity must lead to the death of sexual difference. See, for example, Kelly Oliver's argument that Irigaray's emphasis on the two is "a strategic move to open up multiplicity [. . . ]. [I]n order to get multiplicity we must first have two" (209).
3 Elsewhere in I Love to You, Irigaray suggests that "[t]he natural is at least two: male and female" (35, emphasis added; see also 37). While this suggestion leaves open the possibility of more than two sexes, Irigaray nevertheless adds: "[W]e should make reality the point of departure: it is $t w o$ " (35). Perhaps Irigaray's insistence on twoness can be traced to her account of birth: "I am born of man and of woman, and genealogical authority belongs to man and to woman" (Democracy 131). However, this paradigm of the two-parent heterosexual family is increasingly challenged by new ways of giving birth and raising children (see, for example, Becker and Shanley).

"The whole of human kind [genre humain] is composed of women and men and it is composed of nothing else. The problem of race is, in fact, a secondary problemexcept from a geographical point of view?-which means we cannot see the wood for the trees, and the same goes for other cultural diversities-religious, economic and political ones" (I Love 47). This idea is reiterated elsewhere: "Woma(e)n and ma(e)n are therefore different, more different than Black and White, Catholic and Moslem, Western and Oriental" (Democracy 152). In Between East and West, Irigaray gives a cautious endorsement to mixed-race families but warns that they might also trigger "instinctual resurgences" threatening increased domination and submission if not grounded in a respect for sexual difference (144).

5 Irigaray places her hopes for the ultimate expression of sexual difference in "the relations between man and woman, first and foremost in the couple" (I Love 26 ; see also 27, 28, 30). "[E]ngaging 
with a person of my own gender is threatened with superficiality, dissolution, with an unethical sensibility as long as there are no just institutions appropriate to it" (146). "The wedding between man and woman realizes the reign of spirit. Without it, there is no spirit. Any universal corresponding to a single gender or claiming to be neuter sins against spirit. And to sin against spirit is absolute [...]. Sinning against spirit can arise from infidelity to a proper identity or from depriving the other of the intentionality appropriate to his or her gender" (147).

See Murphy for a critical response to Irigaray's dismissal of androgyny and of women's use of reproductive technologies. See also Mader ("All”); Armour; and Deutscher (Politics 123-41) for perceptive critiques of heterosexism in Irigaray's later work. Both Grosz (347-48) and Deutscher (Politics 78 ) also find resources in Irigaray's work for challenging heteronormativity and reshaping the significance of both heterosexual and homosexual relationships through an opening of sexual difference.

7 For a critical exchange on Stone's account of Irigaray's realist essentialism, see Deutscher ("Recastings"), Mader ("Somatic"), and Stone ("Unthought").

8 Stone draws on Nietzsche for her preliminary account of multiplicity. For Nietzsche, the body is composed of active and reactive forces or drives, all of which seek to satisfy themselves at the expense of the others, but which for this reason are mutually limiting. These forces are preconscious; they exhibit themselves in bodily patterns or rhythms, and they each seek to interpret their situation in ways that increase their power (Luce 78-79).
"Not being naturally clustered into sex-defining groups, drives/ forces simply form a multiplicity, elements in a 'multiple play' of possible combinations and relations" (Luce 83). In Stone's view, we would still need a principle of sexual duality in order to explain the existence of naturally existing sexed clusters or groups. While I think a closer emphasis on the duality of active and reactive forces could have given Stone a way to explain duality, and perhaps even sexual duality, within a Nietzschean framework, this is not the approach I wish to take; to the extent that active forces are more closely associated with the male, and reactive with the female, we come no closer to the expression of nonhierarchical sexual difference.

Stone writes: “Irigaray's suggestion that multiple forces could come to expression only via a sexuate culture is worth preserving. It is only if our sexuate culture becomes fully realized-through its cultural expression-that our multiple bodily forces can develop fully as well [. . .]. Because multiple forces can fully develop only once sexual difference is fully realized, any attempt to express these forces directly-bypassing the stage of constituting a sexuate culture-cannot succeed" (Luce 219). This argument, especially in the context of Irigaray's own marginalization of questions of racial difference, unfortunately recalls second-wave feminist arguments that it was necessary to focus on women's oppression before addressing racial, economic, or any other form of oppression. It overlooks the sense in which these differences do not come in separate packages, but are always already formed as significant differences in relation to one another. 
11 While the image of the vanilla plant recalls "that initial hermaphroditism of which a few rudimentary male organs in the female anatomy and female organs in the male anatomy appear to conserve the trace" (Sodom 33), Proust's hermaphrodite should not be confused with Aristophanes' account in Plato's Symposium of an originary wholeness split apart by divine punishment (189d-193e). As Deleuze observes in his reading of Proust: "Here the vegetal theme takes on its full significance, in opposition to a Logos-as-Organism: hermaphroditism is not the property of a now-lost animal totality, but the actual partitioning of the two sexes in one and the same plant" (120).

12 My reading of Proust dovetails here with Penelope Deutscher's reading of the late Irigaray and especially with her account of sexuate genre as an "infinitely displaced and dispersed series of relational differences" (Politics 186; see also $74-89,185-94)$. In this sense, Proust and Irigaray need not be read as offering competing accounts of sexual difference, but rather as engaged in mutually supportive projects for thinking sexual difference beyond the phallacy of the One.

13 Deleuze calls "transsexuality the ultimate level of the Proustian theory of homosexuality" (122). But it is not clear that Deleuze's use of the term transsexuality can be mapped onto current usage. For Deleuze, "this is the basis of transsexuality, according to Proust: no longer an aggregate and specific homosexuality, in which men relate to men and women to women in a separation of the two series, but a local and nonspecific homosexuality, in which a man also seeks what is masculine in a woman, and a woman what is feminine in a man, and this in the partitioned contiguity of the two sexes as partial objects" (121). In this context, transsexuality does not refer to a specific historical practice of identifying with and transitioning to the other sex, but rather to a "transverse sexuality" in which multiple ways of finding pleasure disrupt the otherwise restrictive "molar" concepts of sex and gender. See Prosser for an excellent discussion of transsexuality in its specific historical sense. Some intersex scholars may object to my claim that Proust's approach to sexual difference helps to articulate intersex forms of embodiment, since Proust does not challenge the duality of male and female, but only imagines each body to contain a germ or embryo of both. This approach may seem to efface the specificity of the intersex body, as if everyone were "intersex" in their own way. I recognize this risk, and yet I think Proust's model helps us to articulate the continuum among predominantly male, predominantly female, and a range of intersex bodies, where none is more or less natural than the others and each has its own distinct way of embodying male and female aspects. Even Anne Fausto-Sterling's concept of the five sexes, or a continuum of sexuation, cannot avoid positing male and female as the two poles that structure the continuum ("Five Sexes," "Five Sexes Revisited"). The crucial step is not to multiply the number of sexes, as if each body required its own genus, but rather to find some way of articulating sex and gender that allows any and every body to become intelligible to itself and others. As I will argue, the duality of the sexes is necessary but not sufficient for this task. 
14. For example, Marcel can only find pleasure with Albertine when she is sleeping, so that she is both safely within his possession and also mysterious to him. While this is clearly not an ideal relationship_it leaves Albertine no room to be a subject with whom he is in relation-I would argue that Marcel's fascination with the sleeping Albertine still involves a relation with alterity, if only because Albertine guards her secrets just as effectively, if not more so, while she sleeps. For a more contemporary, nonliterary example of exchanging with others to "fertilize" one's own pleasure, consider the work of the TLC Trust in the United Kingdom, which connects sex workers with disabled clients so that "sexuallydeprived disabled people get laid, and sex workers gain a renewed pride in their work."

15 Kristeva may be referencing Deleuze's remark in Proust and Signs that "the messenger is itself an incongruous part which does not correspond to its message nor to the recipient of the message" (102).

16 Deleuze puts it even more succinctly: "either ... or . . or" (Deleuze and Guattari 12), "and ... and ... and ..." (Deleuze and Guattari 25; Deleuze and Parnet 10).

17 Cixous's articulation of sexual difference in terms of libidinal economies is relevant here. For Cixous, femininity and masculinity refer not to kinds of bodies but to different ways of experiencing pleasure. Femininity circulates in a general economy of the gift, while masculinity circulates in a restricted economy of give-andtake, where every loss must be matched by an equivalent gain. Masculine/feminine economies do not map neatly onto male/ female bodies; even though the feminine writer expresses herself in milk and blood, most of Cixous's examples of l'écriture féminin are men: Shakespeare, Joyce, Genet, and Kleist. However, to the extent that femininity is for Cixous radically multiple, diffuse, and bisexual, and to the extent that it already includes homosexual and heterosexual men (even privileging men as examples of femininity), Cixous's approach might fall prey to Stone's critique that it is a theory of bodily multiplicity rather than a theory of sexual difference. By combining a duality of sexual "parts" with a multiplicity of different ways to exchange pleasure among these parts, I have sought to overcome this potential difficulty.

18 These shifts continue throughout the book, and indeed throughout In Search of Lost Time. Charlus is virile and misogynist for his society friends, feminine and guileless for Marcel when he enters the courtyard, masculine and sexy for Jupien, tedious and maternal (and later criminally insane) for Morel, and so forth.

19 Marcel compares Jupien to one of those "short-styled hermaphroditic flowers of the Primula veris [that] remain sterile for as long as they are being fertilized only by other likewise short-styled Primula veris, whereas they welcome with delight the pollen from the long-styled Primula veris" (Sodom 32). These miraculous cross-fertilizations are more or less standard for Charlus, since he is capable of feeling a wide variety of rare pleasures, including the pleasure that comes from not even touching someone but merely being in their presence, like "those flowers which in a garden are fertilized by the pollen from a neighboring flower that they will never touch" (Sodom 
32), or like "certain flowers [that], thanks to a spring-mechanism, spray the unconsciously complicit, disconcerted insect from a distance" (Sodom 33; see Guermantes $555^{-65}$ for an illustration of this technique in the context of Charlus's relationship with Marcel). Charlus's sexuality exceeds even the terms of this botanical imagery; in the final volume of In Search of Lost Time, for example, Marcel witnesses a very different scene, again as an unseen voyeur, in which Charlus has made elaborate arrangements to be chained and beaten with nail-studded whips in a brothel run by Jupien (Finding 119-48). As complex as it is, the initial encounter between Charlus and Jupien is only one of many scenes of pleasure and desire explored by Proust.

20 This may seem to suggest that, ultimately, the whole male/female duality dissolves into a nonsexuate multiplicity. What is the sense of referring to male and female "parts" if they do not correspond to a biologically real sexual dimorphism? But the worry is misplaced. In the account I am developing here, the significance of sexual difference does not rely upon the existence of two sexed identities, male and female, whose distinction might become blurred if sexual possibilities were multiplied. Rather, male and female become significant terms (to the extent that they are) in relation to a division or septum that generates at least two possibilities as the starting point for sexuate existence.

Similarly, it makes little sense to say that Albertine is or is not a lesbian, or that Morel is gay, straight, lesbian, or bisexualalthough each of these descriptions is plausible enough in its own context.
Deleuze says something similar about the orchid and the wasp: "The wasp becomes part of the orchid's reproductive apparatus at the same time as the orchid becomes the sexual organ of the wasp" $(2-3)$. While the development of this issue exceeds the scope of this essay, we might also say that the bee is the plant's movement, its temporalization, while the plants are the bee's spatialization, its stability or rest. As Deleuze suggests in Proust and Signs, "Perhaps that is what time is: the ultimate existence of parts, of different sizes and shapes which cannot be adapted, which do not develop at the same rhythm, and which the stream of style does not sweep along at the same speed" (101).

Closer still to nature-and the multiplicity of these comparisons is itself all the more natural in that, examined over the course of a few minutes, the same man seemed successively to be a man, a man-bird, or a man-insect, and so on-it was like two birds, the male and the female, the male seeking to advance, the female-Jupienmaking no sign in response to this maneuver, but looking at her new friend without surprise, with an inattentive fixity, adjudged more disturbing no doubt and alone of use, from the moment that the male had made the first moves, and contenting herself with preening herfeathers. (Sodom Io)

The awkward, artificial, and highly stylized seduction ritual of Charlus and Jupien is no more or less "natural" than the mating rituals of certain birds, whose own culture of pleasure is not opposed to the human, but resonates with both formal similarities and specific differences. 
Works Cited
Armour, Ellen. Deconstruction, Feminist Theology, and the Problem of Difference. Chicago: U of Chicago P, 1999 .

Becker, Gaylene. The Elusive Embryo: How Women and Men Approach New Reproductive Technologies. Los Angeles: u of California P, 2000.

Carter, Angela. The Infernal Desiring Machines of Doctor Hoffman. London: Penguin, 1986.

Cixous, Hélène, and Catherine Clément. The Newly Born Woman. Trans. Betsy Wing. Minneapolis: U of Minnesota P, 1986.

Deleuze, Gilles. Proust and Signs. Trans. Richard Howard. New York: Richard Braziller, 1972.

Deleuze, Gilles, and Félix Guattari. A Thousand Plateaus: Capitalism and Schizophrenia. Minneapolis: U of Minnesota P, 1987.

Deleuze, Gilles, and Claire Parnet. Dialogues 2. Trans. Hugh Tomlinson and Barbara Habberjam. New York: Columbia u P, 2002.

Deutscher, Penelope. A Politics of Impossible Difference: The Later Work of Luce Irigaray. Ithaca: Cornell U P, 2002.

"Recastings: On Alison Stone's Luce Irigaray and the Philosophy of Sexual Difference." differences: A Journal of Feminist Cultural Studies 19.3 (2008): 139-49.

Fausto-Sterling, Anne. "The Five Sexes, Revisited." Sciences 40.4 (2000): 18-23.

“The Five Sexes: Why Male and Female Are Not Enough.” Sciences 33.2 (1993): $20-24$.

Grosz, Elizabeth. "The Homo and the Hetero: The Sexual Ethics of Luce Irigaray." Engaging with Irigaray: Feminist Philosophy and Modern European Thought. Ed. Carolyn Burke, Naomi Schor, and Margaret Whitford. New York: Columbia U P, 1994. 335-50.

Guenther, Lisa. The Gift of the Other: Levinas and the Politics of Reproduction. Albany: SUNY P, 2007 .

Irigaray, Luce. Between East and West: From Singularity to Community. Trans. Stephen Pluhácek. New York: Columbia u P, 2001.

Continuum, 2000 .

Democracy Begins between Two. Trans. Kirsteen Anderson. New York: An Ethics of Sexual Difference. Trans. Carolyn Burke and Gillian C. Gill. London: Continuum, 2004.

"The Fecundity of the Caress: A Reading of Levinas, Totality and Infinity Section 4 B, 'The Phenomenology of Eros.'" Face to Face with Levinas. Ed. Richard A. Cohen. Albany: SUNY P, 1986. 231-56.

. I Love to You: Sketch of a Possible Felicity in History. Trans. Alison Martin. New York: Routledge, 1996. Routledge, 1993 .

Je, Tu, Nous: Toward a Culture of Difference. Trans. Alison Martin. New York: Sexes and Genealogies. Trans. Gillian C. Gill. New York: Columbia u P, 1993. 
Cornell uP, 1985 .

This Sex Which Is Not One. Trans. Catherine Porter and Carolyn Burke. Ithaca:

Kristeva, Julia. Time and Sense: Proust and the Experience of Literature. Trans. Ross Guberman. New York: Columbia U P, 1996.

Mader, Mary Beth. "All Too Familiar: Luce Irigaray's Recent Thought on Sexuation and Generation." Continental Philosophy Review 36 (2003): 367-9o.

"Somatic Ontology: Comments on Alison Stone's Luce Irigaray and the Philosophy of Sexual Difference." differences: A Journal of Feminist Cultural Studies 19.3 (2008): $126-38$.

Murphy, Ann V. "Beyond Performativity and Against 'Identification': Gender and Technology in Irigaray." Returning to Irigaray: Feminist Philosophy, Politics, and the Question of Unit. Ed. Maria Cimitile and Elaine P. Miller. Albany: SUNY P, 2006.

Oliver, Kelly. Witnessing: Beyond Recognition. Minneapolis: u of Minnesota P, 2001.

Prosser, Jay. Second Skins: The Body Narratives of Transsexuality. New York: Columbia $\mathrm{UP}, 1998$.

Proust, Marcel. Finding Time Again. Trans. Ian Patterson. Vol. 6 of In Search of Lost Time. The Guermantes Way. Trans. Mark Treharne. Vol. 3 of In Search of Lost Time.

.In Search ofLost Time. 6 vols. Ed. Christopher Prendergast. London: Penguin, 2003.

Sodom and Gomorrah. Trans. John Sturrock. London: Penguin, 2003. Vol. 4 of In Search of Lost Time.

Shanley, Mary Lyndon. Making Babies, Making Families: What Matters Most in an Age of Reproductive Technologies, Surrogacy, Adoption, and Same-Sex and Unwed Parents. Boston: Beacon, 2002.

Stone, Alison. Luce Irigaray and the Philosophy of Sexual Difference. Cambridge: Cambridge $\mathrm{UP}, 2006$.

"Unthought Nature: Reply to Penelope Deutscher and Mary Beth Mader." differences: A Journal of Feminist Cultural Studies 19.3 (2008): 150-57.

TLC Trust. "Welcome to the TLC Trust." http://www.tlc-trust.org.uk/index.ph. (accessed 15 Mar. 2010). 